\title{
Determinants of dioxins and furans in blood of non-occupationally exposed populations living near Portuguese solid waste incinerators
}

\author{
M. Fátima Reis ${ }^{\mathrm{a}, *}$, J. Pereira Miguel ${ }^{\mathrm{a}}$, Carla Sampaio ${ }^{\mathrm{a}}$, Pedro Aguiar ${ }^{\mathrm{b}}$, \\ J. Maurício Melim ${ }^{\mathrm{c}}$, Olaf Päpke ${ }^{\mathrm{d}}$ \\ ${ }^{a}$ Institute of Preventive Medicine, Faculty of Medicine, University of Lisbon, Av. Prof. Egas Moniz, Edificio Egas Moniz, \\ Piso 0, Ala C, 1649-028 Lisbon, Portugal \\ ${ }^{\mathrm{b}}$ National School of Public Health, New University of Lisbon, Av. Padre Cruz, 1600-560 Lisbon, Portugal \\ ${ }^{c}$ Public Health Regional Department, Rua das Hortas, 30, 9050-024 Funchal, Madeira, Portugal \\ ' ERGO Forschungsgesellschaft mbH, Geierstrasse 1, 22305 Hamburg, Germany
}

Accepted 26 May 2006

Available online 22 January 2007

\begin{abstract}
Biomonitoring of dioxin body burden, as evaluated by PCDD/F levels in blood, has been carried out in a total of 138 adults from general population living in the vicinity of solid waste incinerators in Portugal. Measurements were performed included in cross-sectional surveys within two Environmental Health Surveillance Programs launched in response to ecotoxicological concern in relation to solid waste incinerators near Lisbon and in Madeira Island. Overall conclusion from first published results is indicative that dioxin exposure of global populations cannot be related to the emissions of these facilities, meaning that dioxin sources control seems to be effective in relation to both incinerators. Main objective of present work was to investigate potential determinants of dioxin levels in the studied populations. Findings from this investigation also suggest that incineration does not impact on dioxin blood levels of nearby residents. Follow-up of a small group of individuals (22) from Lisbon gives preliminary indication on temporal control effectiveness of the Lisbon facility. Regarding comparison between PCDD/F levels from Lisbon and Madeira communities, individuals from Lisbon show higher median PCDD/F levels, likely to be better explained by more highly polluted areas in Lisbon than by eventual differences in dietary habits of the studied groups. In fact, analysis performed on the diet of both groups (not detailed in the present study) does not show a statistically significant difference in relation to any of the most relevant foodstuffs in the context of dioxin exposure. Comparison between Lisbon and Madeira in relation to pattern of the single congeners for PCDD/Fs shows a very similar profile. The highest contributions to the PCDD/Fs toxicity came from 12378-PCDD, 23478-PCDF, Hexa-CDD, 2378-TCDD and Hexa-CDF.
\end{abstract}

(C) 2006 Elsevier Ltd. All rights reserved.

Keywords: Incinerators; Biomonitoring; Blood; PCDD/Fs; Portugal

\section{Introduction}

Human biomonitoring is becoming more and more considered as an essential tool to assess relevant exposure of the population. Much more than by the analysis of the quality of the environment as such through air, water, food

\footnotetext{
* Corresponding author. Tel.: +351 21 7985100x47064; fax: +351 21 7999487.

E-mail address: mfreis@fm.ul.pt (M.F. Reis).
}

and soil monitoring programmes, biomonitoring in humans provides a possibility to assess human exposure to environmental pollutants and potential health effects of such exposure. It is a reliable source of information when linked to toxicological and environmental monitoring data. Moreover, biomonitoring takes into consideration the differences between individuals with regard to uptake, which are due to differences in hygiene, breathing characteristics, etc., and metabolisation and elimination. Measuring internal dose of chemicals rather than exposed 
dose, biomonitoring accounts for exposure from all sources, pathways and routes of absorption. Therefore, it has several advantages over environmental monitoring for large-scale survey programs, when objective is to monitor exposure to relevant chemicals and to determine spatial and temporal trends of human exposure to those chemicals. In addition, biomarkers are more directly linked to the adverse health effects that one attempts to prevent than any environmental measurement. Although not providing information on health effects a priori, within the continuum "source emissions-environmental concentrations-exposure-human biomonitoring-health effects", human biomonitoring is much closer to health effects than environmental monitoring (Casteleyn, 2004).

Polychlorinated dibenzo- $p$-dioxins (PCDDs) and polychlorinated dibenzofurans (PCDFs), collectively referred to as dioxins, are unwanted by-products in ultra trace amounts from many industrial and thermal processes (Fiedler, 1996; Anderson and Fisher, 2002; Kim et al., 2004). Among the thermal sources, particularly solid waste incinerators have been identified as a major source of dioxins during the 1980s and early 1990s (Quaß et al., 2000, 2004; Allsopp et al., 2001). Owing to the diversity of sources, these halogenated aromatic compounds (some extremely toxic) are ubiquitous in the environment and have been found in almost every compartment of the global ecosystem, including human samples (Travis and Hattemer-Frey, 1991; Van den Heuvel et al., 2002; Yang et al., 2002). Moreover, because PCDDs and PCDFs are resistant to both biological and chemical degradation and have a lipophilic nature, these compounds bioaccumulate and sometimes biomagnify in the food chain, mainly in the lipids, increasing the potential hazard for human and animal health.

Modern technologies are more effective in controlling dioxin emissions from the incineration processes leading to evident decline in atmospherically impacted media, human dietary intake and body burden (Meneses et al., 2004). However, public and scientific concern still exists in relation to the consequences of incineration, determining a huge need of developing specific surveillance programs to assess the potential impact of these processes on the environment of the influence areas as well as on the population residing in their vicinity.

Since 1999, a modern municipal solid waste incinerator VALORSUL - has been operating in the Metropolitan Area of North-Lisbon, Portugal. In order to get a reliable data basis on the body burden of PCDD/Fs in the population residing in the vicinity of the plant, susceptible of identifying time trends and possible regional differences, a biomonitoring program was implemented in the ambit of the VALORSUL Environmental Health Surveillance Program, referred elsewhere (Reis et al., 2002). Repeated cross-sectional studies and, as much as possible, regular examinations of blood samples to determine $\mathrm{PCDD} / \mathrm{F}$ levels, are included in this biomonitoring program.
Also in Portugal but far from Lisbon (in Madeira Island), an old incinerator has been updated and, through modern technology, recommenced operating on June 2002, to incinerate solid waste, either municipal, or from hospital or slaughterhouse. Relatively to this incinerator, another Environmental Health Surveillance Program has been implemented, with the main goal of monitoring magnitude as well as spatial and temporal trends of specific indicators of both exposure to the environmental agents of concern and potential adverse health effects in subjects living in the area under influence of the facility.

Within the scope of both Environmental Health Surveillance Programs, several human biomonitoring projects have therefore been started, some of them focussed in dioxins and dioxin-like compounds. In a first phase, baseline levels for human exposure to those pollutants would be established through their determination in blood from subjects living in the area under potential influence of the facility and, for comparison, from individuals with farther place of residence and work. Measurements are repeated periodically in order to monitor space and time trends. The protocol of both programs has been approved by the Ethics Committee of the Lisbon Faculty of Medicine and published in detail elsewhere (Miguel et al., 2001).

In Lisbon two examinations have already been carried out as repeated cross-sectional surveys, which included analysis of blood samples from general population to determine PCDD/F levels. One of the examinations has started on 1999, before incinerator regular operation to establish baseline levels in both study areas, and another, during first two years, to monitor space and time trends. A third examination is now in progress.

Concerning Madeira Island, baseline levels have already been established and examination is now being repeated to enable first evaluation of the potential specific impact of the updated solid waste incinerator on human exposure to dioxins and consequently on public health.

Main results of the undertaken studies have recently been published (Reis et al., 2004a,b; Sampaio et al., 2004a,b). Overall conclusion points to a non-significant regional difference on dioxin levels when exposed and control populations relative to each incinerator are considered. This may indicate that dioxin exposure of global populations, as estimated by blood PCDD/F levels in the general population, cannot be related to the emissions from the studied facilities, meaning that dioxin sources control seems to be effective in relation to both incinerators.

Because the same questionnaire has been administered to both populations and in the different examinations to gather data on individual characteristics, smoking and drinking habits, specific dietary habits (mainly consumption of meat, fish, dairy and local food), professional activity and specific hobbies, residential and work conditions, physical activity, past history of diseases and treatments, it will be possible to investigate potential determinants of the dioxin levels in the studied populations. This is the main purpose of the present investigation. 


\section{Experimental}

\subsection{Sampling}

Apparently healthy, 18-65 years aged adults, not-known occupationally exposed to dioxins, living at residing area for more than one year volunteered, after written informed consent was given, to participate in blood biomonitoring studies. Within each community (Lisbon and Madeira), participants were classified as exposed and controls, depending on specific living area far from a solid waste incinerator for a distance pre-defined by specific Environmental Impact Study. Similar relevant socio-demographic characteristics in exposed and controls were ensured, in order to avoid between-group bias.

Blood samples have been collected every two years, starting on 1999 in Lisbon and on 2002 in Madeira, to establish baseline levels and to monitor space and time trends. At working place in Lisbon and in local health centres in Madeira, fasting participants gave both venous blood samples (about $80 \mathrm{ml}$ ), collected by health professionals, and, via questionnaire, data on individual characteristics, smoking and drinking habits, specific dietary habits (mainly consumption of meat, fish, dairy and local food), professional activity and specific hobbies, residential and work conditions, physical activity, past history of diseases and treatments and, more recently for women, parity, number of breastfed children and breastfeeding duration.

In total, 138 apparently healthy adults have already been examined relatively to dioxin body burden, 33 and 85 from Lisbon, during first and second observational period, respectively, and 20 from Madeira. Due to very serious follow-up losses mainly related with blood sample volume, only 22 of the participants from Lisbon community have been followed over time, contrarily to what had been previously planned to identify eventual changes in the individual PCDD/F levels.

Blood samples were frozen $\left(-20^{\circ} \mathrm{C}\right)$ and subsequently analysed to measure the concentration of polychlorinated dibenzo-p-dioxins (PCDDs), polychlorinated dibenzofurans (PCDFs), as well as certain polychlorinated biphenyls
(PCBs) known to have "dioxin-like" properties, only for a limited number of samples.

\subsection{Analytical procedures}

Blood was collected in chemically cleaned glass bottles and frozen within the next few hours. All samples were shipped on dry ice by an international courier to ERGO Research Laboratory in Hamburg, Germany for dioxin analysis. The samples were stored frozen until analysed. Seven dibenzodioxin, and ten dibenzofuran congeners were analysed by high resolution gas chromatography coupled with high resolution mass spectrometry. All analyses were performed following the isotope dilution method. The 17 native and ${ }^{13} \mathrm{C}$-labelled standards used were obtained from Cambridge Isotope Laboratories, USA and from Wellington laboratories, Guelph, Canada.

Solvents were supplied by Promochem (cyclohexane, isopropanol, hexane and dichloromethane) and Mallinckrodt (ethanol, toluene). Silica gel, alumina oxide, sodium sulphate, potassium oxalate sulphuric acid and potassium hydroxide were obtained from Merck. The method is described in detail by Päpke et al. (1989).

Levels of dioxin compounds are reported in $\mathrm{pg} / \mathrm{g}$, or parts per trillion (ppt), lipid, and in World Health Organization (WHO) dioxin toxic equivalents (TEQs). In addition, lipid content in each sample was gravimetrically measured. Pooled blood samples and method blank samples were also analysed as part of a quality control procedure (QA/QC).

Before extraction all 17 2,3,7,8 substituted ${ }^{13} \mathrm{C}$-labelled PCDDs/PCDFs are added to the samples. After spiking, the samples are extracted with adequate solvents using a solid/liquid extraction for blood. The clean up is done on multicolumn systems involving carbon-on-glass fibre. The measurement is performed by means of high resolution gas chromatography/high resolution mass spectrometry (HRGC/HRMS) on a Micromass AutoSpec operating at a resolution of 10000 using a DB-5 capillary column. The quantification is carried out by the isotope dilution method.

Table 1

Comparative analysis of WHO-TEQs (pg/g fat) in blood across areas of residence, communities and sex, and correlation between age and dioxin levels

\begin{tabular}{|c|c|c|c|c|c|c|c|c|c|}
\hline Variables & & $n$ & Median & Mean & SD & Min. & Max. & $R_{\mathrm{s}}$ & $p$ \\
\hline \multirow[t]{2}{*}{ Area } & Exposed & 65 & 14.7 & 15.8 & 6.2 & 4.0 & 34.3 & - & $0.835^{\mathrm{a}}$ \\
\hline & Control & 51 & 15.1 & 15.3 & 5.8 & 5.3 & 32.3 & & \\
\hline & Madeira & 20 & 9.6 & 11.0 & 5.7 & 5.2 & 28.8 & & \\
\hline \multirow[t]{2}{*}{ Sex } & Male & 58 & 13.7 & 14.5 & 5.2 & 4.0 & 28.8 & - & $0.079^{\mathrm{a}}$ \\
\hline & Female & 56 & 15.6 & 16.7 & 6.7 & 5.2 & 34.3 & & \\
\hline
\end{tabular}

$R_{\mathrm{s}}-$ Spearman's correlation coefficient.

a Mann-Witney $U$-test.

b Spearman's correlation analysis. 
The analytical method applied for blood was successfully tested in various national and international quality control studies and proficiency tests (WHO, 1995; ICDF, 2001).

\subsection{Statistical analysis}

Data base management was performed using Microsoft Access 2000 (9.0.3821 SR-1) and, for the statistical analyses, SPSS software version 12.0 for Windows was used. Significance level was generally fixed at $\alpha=0.05$. To describe categorical variables, counts and percentages have been used. Numerical variables were described by their arithmetic means, medians, standard deviation and range of variation. Since PCDD/F levels suggest some deviation from normal distribution, Mann-Whitney test was used for comparative analysis across areas of residence, communities and sex, and Wilcoxon test for paired samples over time. The relationship between age and PCDD/F levels was estimated by computing Spearman's correlation coefficient.

When PCDD/F levels were recoded to percentage of results above median or 75 th percentile, $\chi^{2}$-test was used to study relationship between these variables and area of residence, community and sex and Mann-Whitney test for the relationship with age. In order to estimate magnitude of statistical association through odds ratio adjusted for covariates, multiple logistic regression has been used, considering as dependent variable $\mathrm{PCDD} / \mathrm{F}$ levels with cut-off in median and in 75th percentile. These cut-off values are arbitrary numbers commonly used to identify, within a population, the cases with higher values of contamination and thus higher risk for the related adverse health effects. To decide on variables to enter and stay in the multiple model, environmental health relevance in bivariable analysis and missing values lesser than $1 \%$ were the criteria.

\section{Results and discussion}

Table 1 shows comparative analysis of $\mathrm{PCDD} / \mathrm{F}$ blood levels across areas of residence (exposed and non-exposed or control), communities (Lisbon and Madeira) and sex, as well as correlation between age and dioxin levels. Results are given in pg WHO-TEQs per gram of fat. From these results it can be seen the non-existing statistically significant differences between exposed and non-exposed (control) individuals $(p=0.835)$, being median and mean blood PCDD/F levels very similar in both population groups. Same result is confirmed in Table 2, when cut-offs in median as well as in 75th percentile of PCDD/F levels are considered, due to the fact that statistically significant differences are not found $(55.6 \%<$ median versus $56.8 \% \geqslant$ median; $p=0.894)$ and $(55.1 \%<75$ th percentile versus $61.1 \% \geqslant 75$ th percentile; $p=0.637$ ). From a statistical perspective, these are very interesting findings for the aims of the present investigation, since they suggest

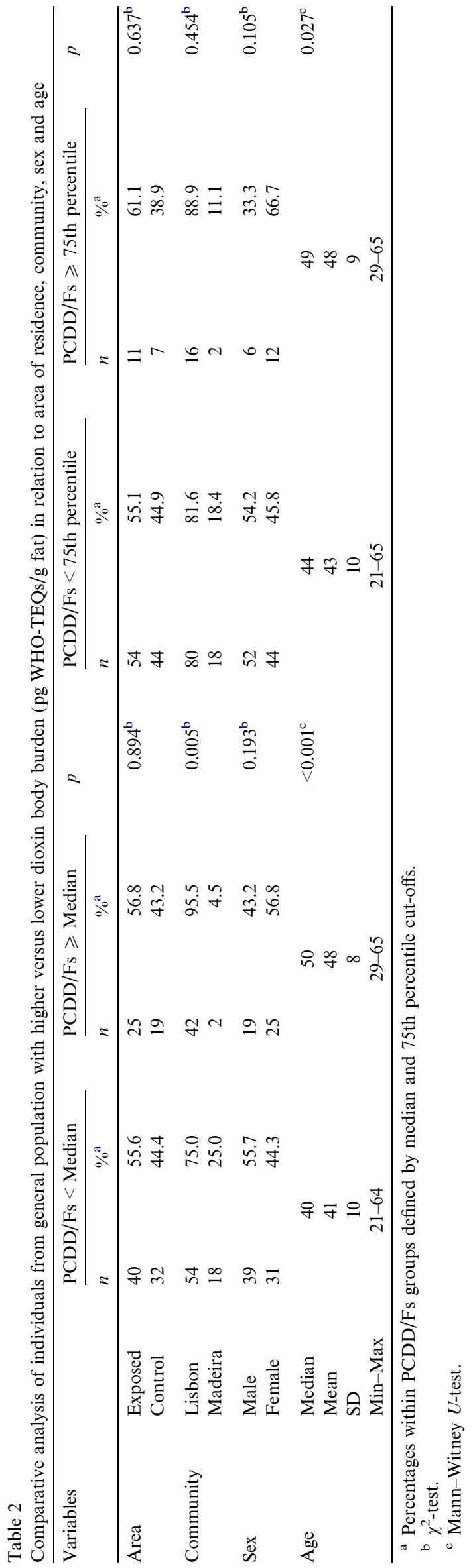


confirmation of previous conclusions (Reis et al., 2004a; Sampaio et al., 2004a) on the dioxin sources control effectiveness in relation to both incinerators under study.

Concerning other variables in Table 1 (namely sex, community and age), distinct conclusions can be drawn: in relation to sex, there is a suggestion for a slightly trend for higher PCDD/F levels in women, although differences of the dioxin blood levels for both sexes are not statistically significant $(p=0.079)$; on the contrary, regarding studied communities (Lisbon and Madeira), individuals from Lisbon show higher median PCDD/F levels when compared with those from Madeira (15.4 and 9.6 pg WHO-TEQ/g fat, respectively), being differences statistically significant $(p<0.001)$. Differences between dioxin levels for community are not confounded by age (Table 3 ) since differences between Lisbon and Madeira in relation to age are not statistically significant and observed differences between means and between medians are not relevant.

Having in mind a non-existing association between dioxin exposure from incinerators under study and dioxin body burden in the population residing in their vicinity, the PCDD/F levels in Lisbon community may be attributed to alternative sources not present or are not so intensive in Madeira. In normal circumstances, the free-living population diet is the major pathway of human dioxin exposure (Liem et al., 2000; Van Leeuwen et al., 2000; Meneses et al., 2004). Therefore, different dietary habits in these distinct Portuguese populations could at least partially explain the identified difference between their dioxin exposures. However, analysis performed on the diet of both groups (not detailed in present study) does not show a statistically significant difference in relation to any of the most relevant foodstuffs in the context of dioxin exposure. It can then be assumed that the identified higher dioxin body burden in Lisbon might be due to higher dioxin load from industry and traffic, potential important primary sources of dioxins, that are present in Lisbon at a much higher level than in Madeira.

As expected, age is also statistically associated with total TEQs in blood, with a significant correlation for the whole group $(r=0.315 ; p=0.001)$ in a way that elder individuals will have higher PCDD/F blood levels.

Table 2 shows comparative analysis of individuals from general population with higher versus lower dioxin body burden in relation to area of residence, community, sex and age. From this table, several conclusions are evident: (i) $95.5 \%$ of the individuals with levels of $\mathrm{PCDD} / \mathrm{Fs}$ equal to or higher than median are from Lisbon, compared with $75 \%$ of the same individuals with levels lesser than that limit; (ii) this difference is statistically significant ( $p=0.005)$; (iii) when more extreme values are considered (i.e. cut-off in 75th percentile), Lisbon community is more prevalent in higher dioxin body burden compared with lower one, but the association is no longer statistically significant $(p=0.454)$. These results can then suggest that Lisbon is associated with higher dioxin levels but the extreme levels can be relatively homogeneous between Lisbon and Madeira.

To investigate possible influencing factors on dioxin body burden as determined by $\mathrm{PCDD} / \mathrm{F}$ levels in blood from the general population, besides living area of the subjects, community, sex and age, several other personal and environmental variables (namely professional activity and hobbies considered risky for higher exposure, present or past smoking habits, intake frequencies of fruit and vegetables, and preferential consumption of meat or fish) have been studied, using bivariable analysis. Variables such as area of residence, community, sex and age entered and stayed in the multiple model mainly due to their environmental health relevance in bivariable analysis and also missing values lesser than $1 \%$.

By estimating the odds ratios adjusted to covariables through the multiple logistic regression (Table 4), one can confirm importance of age for the dioxin body burden of the general population as well as the statistically significant association between Lisbon community and dioxin levels above median. Identically to what has been concluded from Table 2, also from Table 4 it can be seen that the association between Lisbon community and higher dioxin body burden is no longer statistically significant, when the most extreme levels of PCDD/Fs are considered (cut-off in 75th percentile). The logistic regression analysis also confirms, in statistical terms, the dioxin sources control effectiveness already suggested by the above-mentioned results, given the no statistical association between area of residence and higher dioxin blood levels.

From Lisbon community, 22 individuals, distributed between exposed and control groups, have not been fully

Table 3

Comparative analysis of age (years) in relation to area of residence, community and sex

\begin{tabular}{|c|c|c|c|c|c|c|c|c|c|}
\hline Variables & & & $n$ & Median (years) & Mean (years) & $\mathrm{SD}$ (years) & Min. (years) & Max. (years) & $p$ \\
\hline \multirow[t]{4}{*}{ Age (years) } & \multirow[t]{2}{*}{ Area } & Exposed & 62 & 47 & 45 & 9 & 23 & 65 & \multirow[t]{2}{*}{$0.061^{\circ}$} \\
\hline & & Control & 49 & 41 & 41 & 11 & 21 & 65 & \\
\hline & Community & Madeira & 20 & 41 & 41 & 9 & 26 & 64 & $0.113^{\circ}$ \\
\hline & Sex & Male & 57 & 44 & 45 & 10 & 27 & 65 & $0.320^{\circ}$ \\
\hline
\end{tabular}

\footnotetext{
${ }^{a}$ Mann-Witney $U$-test.
} 
Table 4

Multiple logistic regression analysis relative to higher dioxin blood levels in general population (pg WHO-TEQs/g fat)

\begin{tabular}{|c|c|c|c|c|c|c|}
\hline \multirow[t]{2}{*}{ Covariables } & \multicolumn{3}{|c|}{$\mathrm{PCDD} / \mathrm{Fs} \geqslant$ median } & \multicolumn{3}{|c|}{$\mathrm{PCDD} / \mathrm{Fs} \geqslant 75$ th percentile } \\
\hline & OR & $p_{\mathrm{OR}}$ & $\mathrm{IC}_{\mathrm{OR}}(95 \%)$ & OR & $p_{\mathrm{OR}}$ & $\mathrm{IC}_{\mathrm{OR}}(95 \%)$ \\
\hline Area (exposed) & 0.78 & 0.593 & $0.31-1.95$ & 1.51 & 0.474 & $0.49-4.67$ \\
\hline Age - years & 1.09 & $<0.001$ & $1.04-1.14$ & 1.07 & 0.029 & $1.01-1.14$ \\
\hline Community (Lisbon) & 6.11 & 0.028 & $1.21-30.76$ & 1.06 & 0.947 & $0.20-5.63$ \\
\hline Sex (women) & 1.51 & 0.381 & $0.60-3.78$ & 3.25 & 0.051 & $0.99-10.59$ \\
\hline Model $p$ value & \multicolumn{3}{|c|}{$<0.001$} & \multicolumn{3}{|c|}{0.049} \\
\hline Hosmer \& Lemeshow $p$ value & \multicolumn{3}{|c|}{0.821} & \multicolumn{3}{|c|}{0.508} \\
\hline Predicted $(\%)$ & \multicolumn{3}{|c|}{71.2} & \multicolumn{3}{|c|}{83.8} \\
\hline
\end{tabular}

( ) - Category indicated by the covariable; OR: odds ratio adjusted to covariables.

Table 5

Comparative analysis of WHO-TEQs (pg/g fat) in human blood within the same participants $(n=22)$ with repeated measures in different observational periods

\begin{tabular}{lcll}
\hline & T0-baseline & $\begin{array}{l}\text { T1 (one } \\
\text { year after) }\end{array}$ & $p^{\mathrm{a}}$ \\
\hline Median & 14.6 & 14.1 & 0.131 \\
Mean & 15.5 & 14.6 & \\
SD & 5.4 & 5.5 & \\
Min.-Max. & $6.3-26.2$ & $4.6-24.0$ & \\
\hline
\end{tabular}

${ }^{\mathrm{a}}$ Wilcoxon test.

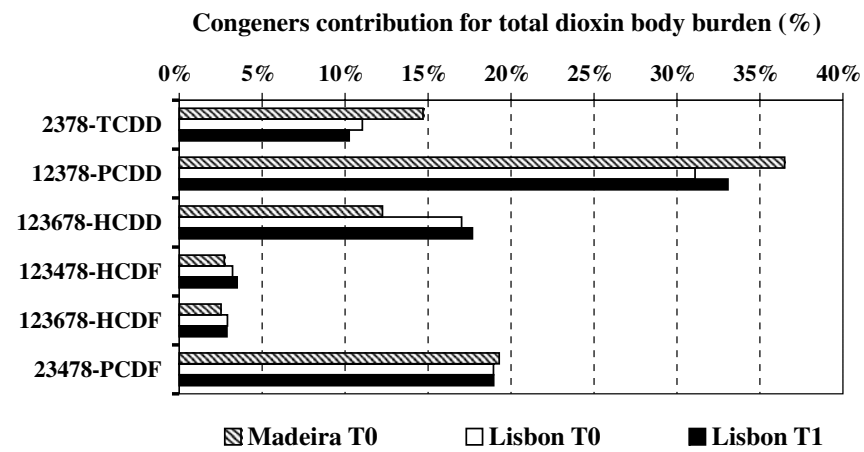

Fig. 1. Contribution $(\%)$ of most relevant individual congeners for the total identified dioxin levels in blood of the general population.

considered in the precedent analysis for independent samples, since they participated in the study during the basal examination and also a year later, during measurements for the evaluation of the first potential specific impact of the incinerator on dioxins exposure. Results for paired determinations show (Table 5), in median and mean terms, a relative homogeneity, that gives preliminary indication also on temporal control effectiveness of the Lisbon incinerator emissions.

The pattern of the single congeners for PCDD/Fs for Lisbon and Madeira (Fig. 1) was very similar being the highest contributions from 12378-PCDD, 23478-PCDF, Hexa-CDD, 2378-TCDD and Hexa-CDF. Altogether, these six individual congeners accounted for about $86 \%$ of the total identified dioxin body burden in the studied groups.

\section{Acknowledgements}

Authors of this study wish to express their gratitude to VALORSUL - Valorização e Tratamento de Resíduos Sólidos Urbanos da Área Metropolitana de Lisboa, Norte and to the Autonomous Region of Madeira, Regional Ministry of Environment and Natural Resources, for the support of the present research partially included in their ongoing Environmental Health Surveillance Programs, which are being developed, under contract, by the Institute of Preventive Medicine - Faculty of Medicine, University of Lisbon. The authors are also very grateful to the technical staff from the Portuguese Institute of Blood for the excellent assistance in fieldwork and sample collection. Very special thanks are also due to the volunteers for their excellent collaboration.

\section{References}

Allsopp, M., Costner, P., Johnston, P., 2001. Incineration and human health. State of knowledge of the impacts of waste incinerators on human health. Greenpeace Research Laboratories, University of Exeter, UK, ISBN 90-73361-69-9.

Anderson, D.R., Fisher, R., 2002. Sources of dioxins in the United Kingdom: the steel industry and other sources. Chemosphere 46, 371381 .

Casteleyn, L., 2004. Biomonitoring, towards more integrated approaches. Children in their environments: vulnerable, valuable \& at risk. In: EEA, WHO Europe and the Collegium Ramazzini Workshop, June 22nd, 2004, Budapest.

Fiedler, H., 1996. Sources of PCDD/PCDF and impact on the environment. Chemosphere 32, 55-64.

International Comparison on Dioxins in Food, 2001. Final Report 2001: 4, Folkehelsa. National Institute of Public Health, Norway, November 2001.

Kim, S.C., Choe, S.H., Na, J.G., Hwang, S.R., Lee, Z.H., Chang, J.Y., Cho, H.J., 2004. Correlations of emission concentrations among PCDDs/PCDFs, co-planar PCBs and HCB from major thermal stationary sources. Organohalogen Compd. 66, 926-930.

Liem, A.K.D., Fürst, P., Rappe, C., 2000. Exposure of populations to dioxins and related compounds. Food Add. Contam. 17, 241-259.

Meneses, M., Schuhmacher, M., Domingo, J.L., 2004. Health risk assessment of emissions of dioxins and furans from a municipal waste incinerator: comparison with other emission sources. Environ. Int. 30, 481-489.

Miguel, J.P., Reis, M.F., Calheiros, J., Carreira, M., Pissarra, M.I., Gomes, P., 2001. Programa de Vigilância Epidemiológica Ambiental da Central de Tratamento de Resíduos Sólidos Urbanos de S. João da 
Talha. Protocolo. Instituto de Medicina Preventiva, Faculdade de Medicina de Lisboa (in portuguese).

Päpke, O., Ball, M., Lis, A., Scheunert, K., 1989. PCDD/PCDF in whole blood samples of unexposed persons. Chemosphere 19, 941-948.

Quaß, U., Fermann, M.W., Bröker, G., 2000. Step towards a European dioxin emission inventory. Chemopshere 40, 1125-1129.

Quaß, U., Fermann, M., Bröker, G., 2004. The European dioxin air emission inventory project - final results. Chemosphere 54, 1319-1327.

Reis, M.F., Miguel, J.P., Pissarra, M.I., Sampaio, C., Calheiros, J., 2002. Infant exposure to $\mathrm{PCDD} / \mathrm{Fs}$ in Portugal: First results from an environmental health survey program near Lisbon. Organohalogen Compd. 55, 247-250.

Reis, M.F., Miguel, J.P., Sampaio, C., Melim, J.M., Aguiar, P., 2004a. First results from dioxins and dioxin-like compounds in the population from Madeira Island, Portugal. Part 1 - Biomonitoring in blood of the general population living near to a solid waste incinerator. Organohalogen Compd. 66, 2736-2742.

Reis, M.F., Sampaio, C., Melim, J.M., Miguel, J.P., 2004b. First results from dioxins and dioxin-like compounds in the population from Madeira Island, Portugal. Part 2 - Biomonitoring in breast milk of women living near to a solid waste incinerator. Organohalogen Compd. 66, 2743-2749.

Sampaio, C., Reis, M.F., Miguel, J.P., Aguiar, P., 2004a. Levels and trends of $\mathrm{PCDD} / \mathrm{Fs}$ in human blood and milk of residents in the vicinity of a modern municipal solid waste incinerator near to Lisbon. Organohalogen Compd. 66, 2813-2817.

Sampaio, C., Murk, A., Reis, M.F., Miguel, J.P., 2004b. Possible additional exposure to dioxin and dioxin-like compounds from waste incineration. Biomonitoring using human milk and animal samples. Organohalogen Compd. 66, 2807-2812.

Travis, C.C., Hattemer-Frey, H.A., 1991. Human exposure to dioxins. Sci. Total Environ. 104, 97-127.

Van den Heuvel, R.L., Koppen, G., Staessen, J.A., Hond, E.D., Verheyen, G., Nawrot, T.S., Roels, H.A., Vlietinck, R., Schoeters, G., 2002. Immunologic biomarkers in relation to exposure markers of PCBs and dioxins in Flemish adolescents (Belgium). Environ. Health Persp. 110, 595-600.

Van Leeuwen, F.X.R., Feeley, M., Schrenk, D., Larsen, J.C., Farland, W., Younes, M., 2000. Dioxins: WHO's tolerable daily intake (TDI) revisited. Chemosphere 40, 1095-1101.

WHO Regional office for Europe: Consultation on the third round of interlaboratory quality control studies on levels of PCBs, PCDDs and PCDFs in human milk, blood, cows milk and fish. EUR/ICP EHAZ 94 05/B03(1), Denmark, 1995.

Yang, J., Shin, D., Park, S., Chang, Y., Kim, D., Ikonomou, M.G., 2002. PCDDs, PCDFs, and PCBs concentrations in breast milk from two areas in Korea: body burden of mothers and implications for feeding infants. Chemosphere 46, 419-428. 